\title{
Posterior cranial fossa dermoid in association with congenital basilar invagination, a craniovertebral junction anomaly and Kippel-Feil syndrome: A potential threat of infective abscess and meningitis
}

\author{
Guru Dutta Satyarthee ${ }^{1 *}$ and Sanjeev Lalwani ${ }^{2}$ \\ ${ }^{1}$ Department of Neurosurgery, Neurosciences Centre, All India Institute of Medical Sciences, New Delhi, India \\ ${ }^{2}$ Department of Forensic Medicine, All India Institute of Medical Sciences, New Delhi, India
}

\begin{abstract}
Intracranial dermoid cysts are uncommon occurrence. The intracranially located dermoid cyst arises from ectoderm, probably derived from cell nest included during the closure of neural tube. The commonest site of intracranial dermoid cyst is posterior fossa. The more common supratentorial tumours are located on skull base, frontal or temporal or suprasellar region. Intracranial dermoid cyst can be associated with complete or incomplete sinus tract, usually ending in an intracranial location of dermoid, which predisposes to risk of meningitis, locally discharging sinus and even abscess formation and associated morbidity. Although the spinal lumbosacral dysraphism association with congenital spinal dermoid tumors is well known, however, the association of craniocervical spinal anomalies and posterior fossa dermoids has been recognized recently, so paucity of literature. Kippel- Feil syndrome may be associated with craniovertebral junction anomaly. In addition, it can be associated with diastematomyelia, syringomyelia, agenesis of corpus callosum, meningocele, ventriculomegaly, porencephalic cyst, cervical spina bifida oculta and spinal stenosis. Authors report an 18-year- old male boy with posterior cranial fossa dermoid with basilar invagination. The association of these two discrete pathologies are extremely uncommon. Both these lesions represent embryological disorder. The pathogenesis and treatment modality along with pertinent literature is reviewed. In extensive PubMed search authors could got only one case report by Goel et al. so, current case represents second such association in the literature. Brief embryological development and management of such association along with pertinent literature is reviewed briefly.
\end{abstract}

\section{Introduction}

The lumbosacral region spina bifida may be associated with intradural spinal dermoid tumours. However, craniovertebral junction anomaly in association with posterior fossa dermoid tumor is very uncommon occurrence. There are isolated reports of posterior fossa dermoid associated with cervical spine fusion anomalies.

\section{Illustration of case}

A-18-year -old college boy presented with history of insidious onset slowly progressive neck pain and difficulty in walking for 6 months. He had no past history of trauma or meningitis. General survey revealed short and webbed neck, low hair line and high arch palate. Neurological examination revealed no abnormality of cranial nerves. Muscle tones were increased in all limbs. Powers in all limbs were grade 4 . All deep tendon jerks were brisk with bilateral plantar extensor response. Cerebellar signs were present. Plain x-ray of craniovertebral junction and cervical spine revealed fixed atlantoaxial dislocation with marked basilar invagination and fusion of spinous process of C 3 to $\mathrm{C} 5$ cervical vertebrae. CT scan revealed presence basilar invagination with Kippel -Fiel syndrome. MRI of craniovertebral junction and cervical spine revealed large tumour in the posterior fossa, showing hypointense signal on T1 weighted image compression at craniovertebral junction with intracerebellar dermoid, showing hypointense signal with basilar invagination with Kippel feil syndrome (Figures 1 and 2) and hyperintense signal on T2 weighted image, sagittal section image showing the tumour.
In a single sitting transoral, odondtoidectomy with suboccipital craniectomy with removal of intradural dermoid along with occipitocervical fusion using contoured rod was carried out. Transoral odontoidectomy was first done, patient was positioned on the striker bed with image intensifier control with Midas drill transoral odointoidectomy was done. Then position was changed to prone position with skull traction in situ. Midline suboccipital craniectomy was done. The dura was opened in the midline. A large dermoid tumour was removed; it was located posterior to the vermis and filling up cisterna magna. It consisted of hair interspersed in the cheesy material. The cyst wall was thin. Histopathological examination of the resected specimen revealed typical feature of dermoid. Postoperative period was uneventful. At the last follow-up 20 months following surgery, $\mathrm{He}$ had improvement of power in all limbs with complete resolution of posterior fossa mass effects.

*Correspondence to: Guru Dutta Satyarthee, MCh, Associate Professor, Department of Neurosurgery, Neurosciences Centre, AIIMS, New Delhi, India, E-mail: duttaguru2002@yahoo.com

Key words: posterior cranial fossa dermoid, craniovertebral anomaly, basilar invagination, cervical fusion anomaly

Received: September 17, 2018; Accepted: September 24, 2018; Published: September 31, 2018 
Satyarthee GD (2018) Posterior cranial fossa dermoid in association with congenital basilar invagination, a craniovertebral junction anomaly and Kippel-Feil syndrome: A potential threat of infective abscess and meningitis

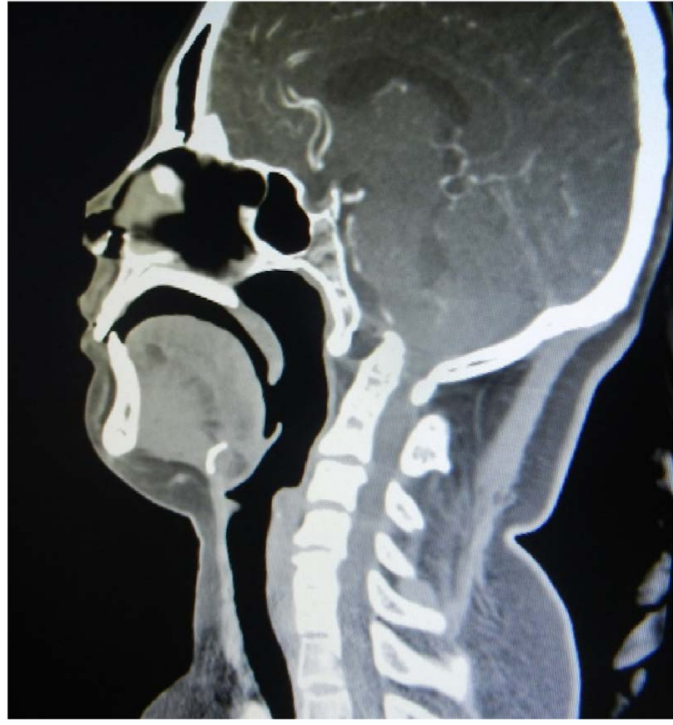

Figure 1. Computed tomography of cervical spine, sagittal reconstruction showing presence of basilar invagination with Kippel -Fiel syndrome

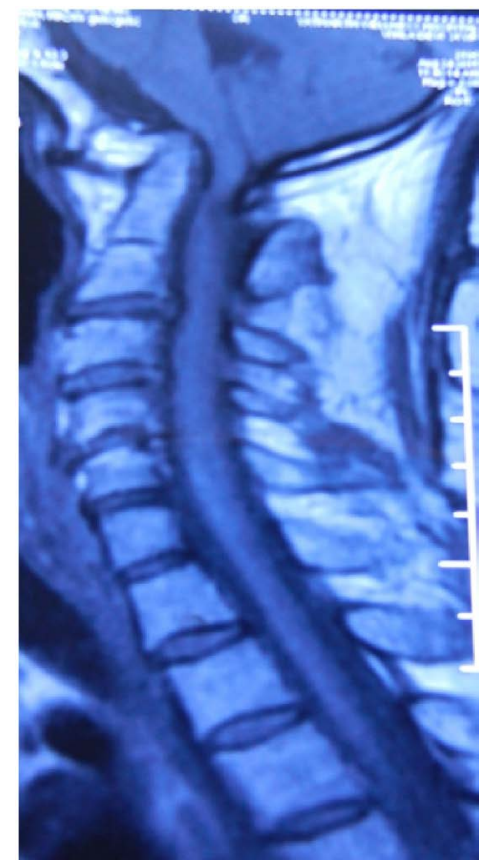

Figure 2. Magnetic resonance imaging $\mathrm{T} 1$ weighted image, sagittal section showing compression at craniovertebral junction showing hypointense signal with basilar invagination with Kippel feil syndrome

\section{Discussion}

Intracranial dermoid cysts are uncommon, it accounts for about 0.1 to $0.7 \%$ of all intracranial tumours [1]. The intracranial dermoid cyst arises from ectoderm, probably derived from cell nest included during the closure of neural tube. The cyst wall is lined with stratified squamus epithelium and mixed appendages of ectodemal origin including sebaceous gland, sweat gland, and hair follicles [2-5]. The cyst content is mixture of decomposed epithelial cells containing keratin, glandular secretion, lipid metabolites, and cholesterol. Rarely dental enamels are also observed [6]. Dermoid cysts are found in supratentorial and infratentorial compartment and within the spinal canal [7]. The commonest location of intracranial dermoid cyst is posterior fossa. The more common supratentorial tumours are located on skull base, frontal or temporal or suprasellar region. It can present at any age, but most common at 2 nd and 3 rd decades, of life.

The clinical symptomatology is variable rarely it may be detected incidentally [8]. However, most patient presents with seizure, longstanding headache [6,7]. It may present with cyst rupture, meningismus, vasospasm, increased intracranial pressure, dementia and possible focal neurological deficits. Death can be as consequence of rupture of dermoid cyst [9]. Intracranial dermoid cyst can be associated with complete or incomplete sinus tract, usually ending in an intracranial location of dermoid [5]. Patient may even present with repeated episodes of meningitis or cerebellar abscess [1]. However, our case presented with only motor deficit, but he had not suffered from infective complication i.e. abscess or meningitis. Kippel- Feil syndrome may be associated with craniovertebral junction anomaly. In addition, diastematomyelia, syringomyelia, agenesis of corpus callosum, meningocele, ventriculomegaly, porencephalic cyst, cervical spina bifida oculta and spinal stenosis. $52 \%$ cases of Kippel- Fiel syndrome had classical triad of short neck, low hairline, and limitation of neck movements. However, the association with posterior fossa dermoid is rare. [9-11].

Many hypotheses are postulated $t$ for association of Kippel-Feil syndrome and cranio-verteberal junction anomaly with posterior fossa dermoid. Kippel-Feil syndrome is caused by failure of segmentation of cervical sclerotome. The neural dysgenesis is late feature supposed to occur after formation of entire neuraxis around 22-26 days of embryonic life. Failure of separation of ectodermal epithelium from neuroectoderm, may explain the inclusion of ectodemal element into posterior fossa, which continuously grows and forms dermoid cysts [12]. Gardner postulated Kippel-Feil deformity production is associated with neural and skeletal abnormalities, are produced due to distortion of somites by over distension of the neural tube. The failure of segmentation of cervical sclerotome can produce altered tissue tension at the cranio-vertebral junction region. These promote entrapment of dermal tissue, which give rise to posterior fossa dermoid, which may have associated dermal sinus [13] . Castillo et al. [14] postulated abnormal migration of neural crest might play a role in constellation of associated pathology. Our patient had reducible atlantoaxial dislocation with basilar invagination, which was only reported by Mazmudar and Goel [12].

Congenital fusion of cervical vertebrae is caused by failure of formation and rearrangement of cervical sclerotome in the third to fifth weeks of intrauterine life, when a cleavage of neuroectoderm from epithelial ectoderm along the mid dorsal aspect of embryo may be incomplete, the persistent cutaneous defect may extend from skin into intracranial comportment or end in extradural or sudurally. Mostly tract ends in dermoid [2]. Posterior fossa dermoid may present with symptoms of raised intracranial pressure or meningitis. The pathway of infection is through dermal sinus, dermal sinus on the scalp can be visualized as a punctum or dimple over the occiput [15] .

$\mathrm{X}$-ray of skull may show defect in skull, calcification and rarely fatfluid level. A cranial computed tomography may show associated bone defect, intracranial dermoid or other associated defects. The posterior fossa dermoid cyst should be differentiated from another cystic lesion of posterior cranial fossa including cerebellar abscess. An early defect with few differentiated cells leads to development of dermoid [5]. These are hypodense due to cholesterol and keratin of epithelial cells, having well defined hypodense margin with a slight post contrast peripheral 
Satyarthee GD (2018) Posterior cranial fossa dermoid in association with congenital basilar invagination, a craniovertebral junction anomaly and Kippel-Feil syndrome: A potential threat of infective abscess and meningitis

enhancement produced by capsule nad inflamed pericapsular area. Dermoid cyst has +4 to $+16 \mathrm{HU}$, although hyperdense epidermoid are also reported [5]. CT scan shows a lesion to be very low density, which differs with variability of cyst content, depending on histopathological composition of heterogeneous lesion [8] calcification if present have shell like appearance. The management of these associated pathology should be based on pathology causing neurological deficit [12].

Dipanker et al. [16] reported multiple congenital lesions spread over long segment of spinal axis. The child had thoracic myelocystocele associated with type 1 split cord malformation, low lying tethered cord, dorsal syrinx and sacral agenesis

Satyarthee et al. [17] published a case of Congenital occipital dermal sinus with an underlying dermoid located in the occipital region. A-10- year-old girl was admitted with complaints of fever, headache and vomiting. Neurological evaluation on admission revealed stiff neck with papilloedema involving both eyes. She also had ataxic gaits with cerebellar signs. The computerised tomography of head revealed multiple cerebellar abscesses. She underwent midline suboccipital craniectomy in the emergency; with excision of abscess and developed aseptic meningitis in the postoperative period, which responded to antimicrobial therapy. The treating physician should be aware of such although rare clinical entity as timely surgical intervention can yield good neurological outcome [17].

In 2012, authors analyzed total of 147 cases [18]. Different types of lipoma included conus lipomas (93), filum lipomas (26) and had only lipomeningomyelocele (28). Boys and girls were almost equally represented. The age of patients at the time of surgery ranged from 15 days to 34 years with an average of 5.2 years. Neurological deficits were present in 101 patients. The patients with neurological deficits were older in comparison to those neurologically intact (average age 6.2 versus 2.8 years, respectively). Difference in age between the two groups was statistically significant (P value 0.03 ). Neurological deterioration was observed in 8 patients following surgery. In the symptomatic group, nine patients showed improvement in neurological status after surgery.

\section{Conclusion}

The patient presenting with cervical spine fusion anomaly, the imaging of posterior fossa is advised to exclude congenital posterior cranial fossa dermoid cyst and associated congenital craniovertebral junction anomaly. The aim of surgery should be directed to pathology, which is symptomatic. However, the surgical management has to tailored for individual patient

\section{References}

1. Diekmann-Guiroy B, Huang PS (1989) Klippel-Feil syndrome in association with a craniocervical dermoid cyst presenting as aseptic meningitis in an adult: case report. Neurosurgery 25: 652-655. [Crossref]

2. Dickey W, Hawkins SA, Kirkpatrick DH, McKinstry CS, Gray WJ (1991) Posterior fossa dermoid cysts and the Klippel-Feil syndrome. J Neurol Neurosurg Psychiatry 54: 1016-1017. [Crossref]

3. Kuribayashi K, Nakasu S, Matsumura K, Matsuda M, Handa J (1993) [Dermoid cyst in the fourth ventricle associated with Klippel-Feil syndrome]. No To Shinkei 45: 747751. [Crossref]

4. Kennedy PT, McAuley DJ (1998) Association of posterior fossa dermoid cyst and Klippel-Feil syndrome. AJNR Am J Neuroradiol 19: 195. [Crossref]

5. Schijman E, Monges J, Cragnaz R (1986) Congenital dermal sinuses, dermoid and epidermoid cysts of the posterior fossa. Childs Nerv Syst 2: 83-89. [Crossref]

6. Smith AS, Benson JE, Blaser SI, Mizushima A, Tarr RW, et al. (1991) Diagnosis of ruptured intracranial dermoid cyst: value MR over CT. AJNR Am J Neuroradiol 12: 175-180. [Crossref]

7. Lunardi P, Missori P (1991) Supratentorial dermoid cysts. J Neurosurg 75: 262-266. [Crossref]

8. Hamer J (1980) Diagnosis by computerized tomography of intradural dermoid with spontaneous rupture of the cyst. Acta Neurochir (Wien) 51:219-226. [Crossref]

9. Oursin C, Wetzel SG, Lyrer P, Bächli H, Stock KW (1999) Ruptured intracranial dermoid cyst. J Neurosurg Sci 43: 217-220. [Crossref]

10. Avery LW, Rentfro CC (1936) The Kippel- Feil syndrome: a pathological report: Arch Neurol Psychiat 36: 1068-1076.

11. Whittle IR, Besser M (1983) Congenital neural abnormalities presenting with mirror movements in a patient with Kippel- Feil syndrome, Case report. J Neurosurg 59; 891894.

12. Muzumdar D, Goel A (2001) Posterior cranial fossa dermoid in association with craniovertebral and cervical spinal anomaly: report of two cases. Pediatr Neurosurg 35: 158-161. [Crossref]

13. Gardner WJ (1979) Klippel-Feil syndrome, iniencephalus, anencephalus, hindbrain hernia and mirror movements: overdistention of the neural tube. Childs Brain 5: 361379. [Crossref]

14. Castillo M, Scatliff JH (1998) Association of posterior fossa dermoid cyst and KippelFeil syndrome (Comment to letter). Am j Neuroradiol 19: 196.

15. PENNYBACKER J, TYTUS JS (1956) Pearly tumours in relation to the central nervous system. J Neurol Neurosurg Psychiatry 19: 241-259. [Crossref]

16. Dipanker M, Satyarthee GD, Sharma BS (2015) A rare case of thoracic myelocystocele associated with type 1 split cord malformation with low lying tethered cord, dorsal syrinx and sacral agenesis: Pentad finding $J$ Neurosci Rural Pract. 6: 87-90.

17. Satyarthee G D, Satyarthee S (2016) Association of Occipital Dermal Sinus with Intracerebellar Epidermoid and Abscesses. American Journal Clin Neurol Neurosurg 2: $34-36$

18. Kumar A, Mahapatra AK, Satyarthee GD (2012) Congenital spinal lipomas: Role of prophylactic surgery. J Pediatr Neurosci 7: 85-89. [Crossref]

Copyright: (C2018 Satyarthee GD. This is an open-access article distributed under the terms of the Creative Commons Attribution License, which permits unrestricted use, distribution, and reproduction in any medium, provided the original author and source are credited. 